NAZARENO NRX; PEREIRA AS; SILVA GO; CASTRO CM; BERTONCINI O; MEDEIROS CAB; HIRANO E; GOMES CB; CAMPOS JF. 2015. IPR CRIS: Cultivar rústica de batata. Horticultura Brasileira 33: 404-408. DOI: http://dx.doi.org/10.1590/S0102-053620150000300022

\title{
IPR CRIS: Cultivar rústica de batata
}

\author{
Nilceu RX Nazareno ${ }^{1}$; Arione S Pereira ${ }^{2}$; Giovani O Silva ${ }^{3}$; Caroline M Castro²; Odone Bertoncini ${ }^{3}$; \\ Carlos AB Medeiros ${ }^{2}$; Elcio Hirano ${ }^{3}$; Cesar B Gomes²; Jocemar F Campos ${ }^{1}$ \\ ${ }^{1}$ Instituto Agronômico do Paraná, IAPAR, Pólo Regional de Pesquisa de Curitiba, Curitiba-PR, Brasil; nilceu@iapar.br; ${ }^{2}$ Embrapa Clima \\ Temperado, Pelotas-RS, Brasil; ${ }^{3}$ Embrapa Produtos e Mercado, Canoinhas-SC, Brasil
}

\section{RESUMO}

Em função de sua rusticidade, a cultivar IPR Cris é recomendada para sistemas de produção agroecológicos e para a agricultura familiar. Todavia, dada a aparência de seus tubérculos ovalados, gemas rasas e película não áspera, também pode ser utilizada em sistemas convencionais de plantio. 'IPR Cris' tem potencial de consumo para vários tipos de preparo, mas não para fritura industrial. Apresenta moderada resistência de campo para a requeima e não tem sido observada suscetibilidade à sarna comum; com potencial produtivo semelhante às cultivares atualmente em produção. Uma característica interessante que desponta na 'IPR Cris' é seu longo período de dormência, que por um lado desfavorece o plantio dos tubérculos semente na safra seguinte, por outro, garante ao pequeno produtor orgânico um período prolongado para comercialização, sem perda de qualidade dos tubérculos.

Palavras chave: Solanum tuberosum, produção orgânica, resistência à requeima.

\section{ABSTRACT}

IPR Cris: A hardy potato cultivar

Due to its rusticity, the cultivar IPR Cris is recommended for agroecolgical and small holding production systems. However, given its tuber appearance, shallow eyes, and lightly rough skin, this cultivar can also be used in conventional production systems. 'IPR Cris' can be consumed under various cooking ways, but it is not fit for the frying industry. It shows good field resistance to late blight and susceptibility to common scab has not been observed. Its yield potential is similar to the current potato cultivars. Long dormancy is an interesting feature shown by 'IPR Cris' which hampers getting the tuber sprouted for the following season. On the other hand it provides small organic farmers for a prolonged marketing period without loss on tuber quality.

Keywords: Solanum tuberosum, organic production, late blight resistance.

(Recebido para publicação em 23 de outubro de 2014; aceito em 6 de abril de 2015)

(Received on October 23, 2014; accepted on April 6, 2015)

\begin{abstract}
A cultivar de batata (Solanum tuberosum) IPR Cris, codificada como clone PHO 15, é um produto do cruzamento simples (artificial), realizado no Centro Internacional de La Papa (CIP), de interesse geral, para a formação de famílias clonais a serem testadas em países onde a cultura da batata tem importância social e econômica. Dada a amplitude das populações, estas foram introduzidas pelo Iapar em meados da década de 80 identificadas por códigos e, portanto, não se tem a identificação específica desse cruzamento (IAPAR, 2014). As populações foram introduzidas no Iapar na forma de minitubérculos, num total aproximado de 2500 indivíduos, plantados para o primeiro ciclo de seleção na Estação Experimental do Iapar, em Teixeira Soares-PR, na safra de outono/1986.
\end{abstract}

Os primeiros ciclos de seleção foram concentrados na avaliação do nível de resistência à requeima (Phytophthora infestans) dentre outras doenças foliares e no porte ereto de plantas. Por meio de avanços de gerações, o clone PHO 15 se destacou entre outros, pela rusticidade e boa aparência de tubérculos. Esse material, pelas suas características potenciais para um futuro lançamento, foi mantido através de gerações de campo nas Estações Experimentais do Iapar.

Em 2002, uma pequena amostra de tubérculos de IPR Cris foi repassada para um produtor colaborador do Iapar, município de Araucária-PR, para sua avaliação em sistema orgânico de produção. Em 2005, esse material genético foi temporariamente lançado como cultivar Cristina (Pereira et al., 2008). Como houve boa aceitação pelo produtor, a Embrapa Clima Temperado, instituição parceira do Iapar, colaborou na indexação desse clone via cultura de tecidos e testes para indexação de viroses. Ainda sob essa parceria, foi possível a produção de minitubérculos em sistema de hidroponia (Medeiros, 2002), para aumento do número de tubérculos indexados visando à condução de experimentos multilocais de avaliação. Esses experimentos foram conduzidos nas Estações Experimentais do Iapar da Lapa e Londrina e nas dependências da Embrapa Clima Temperado, em Pelotas-RS e da Embrapa Produtos e Mercado, Canoinhas-SC.

Confirmado o potencial do clone PHO 15 como uma provável cultivar para o sistema orgânico de produção e agricultura familiar, planejou-se os vários ensaios de Valor de Cultivo e Uso (VCU) (MAPA, 2007), executados na região centro-sul do Paraná (município da Lapa e Teixeira Soares), sul do Rio 
Grande do Sul (Pelotas) e planalto norte catarinense (Canoinhas), entre as safras de outono/2009 e outono/2012, cujos dados foram submetidos ao MAPA para fins de registro. As cultivares Ágata e Cupido foram utilizadas como testemunhas. Os testes de Distinguibilidade, Homogeneidade e Estabilidade (DHE) foram realizados em ensaios conduzidos nas primaveras de 2010 e 2011, em Pelotas, sob responsabilidade da Embrapa Clima Temperado e complementado com informações de experimentos na Estação Experimental do IAPAR na Lapa. Nestes testes, a cultivar IPR Cris mostrou distinguibilidade, homogeneidade e estabilidade fenotípica e genética.

\section{DESCRIÇÃO VARIETAL}

Segundo os requisitos mínimos para determinação do VCU da batata para inscrição no Registro Nacional de Cultivares (RNC) (MAPA, 2007), IPR Cris apresenta as seguintes características:

Brotos - formato cilíndrico largo, vermelho púrpuro na base e pouca pu- bescência (Figura 1A).

Hastes e planta - a base das hastes é não pigmentada e apresenta delineamento ondulado a dentado da asa. As plantas têm porte ereto (Figura 1B), vigor médio e ciclo longo, fechando o ciclo de desenvolvimento vegetativo entre 110 e 120 dias, dependendo das condições ambientais e de cultivo.

Folhas e folíolos - as folhas são abertas com ângulo de inserção agudo e não há pigmentação na nervura principal. Os folíolos são médios, estreitos, não coalescentes, com ondulação média nas bordas e alta frequência de folíolos secundários (Figura 1C).

Flores e frutos - a presença de inflorescências é alta, com pedúnculo longo e sem pigmentação. As flores são brancas, sem pigmentação interna ou externa da corola (Figura 1D) e a ocorrência de frutos é baixa em média.

Tubérculos - os tubérculos são ovalados, com gemas rasas, película levemente áspera, de coloração amarela e polpa amarela clara (Figura 1E) e fraca tendência ao esverdeamento.

\section{REAÇÃO A DOENÇAS}

'IPR Cris' se caracteriza como moderadamente resistente à requeima $(P$. infestans) e à pinta preta (Alternaria sp.), suscetível às principais doenças bacterianas como canela preta/podridão mole (Pectobacterium spp.) e murchadeira (Ralstonia solanacearum) e moderadamente resistente à sarna comum (Streptomyces spp.), moderadamente resistente ao mosaico \{Potato virus Y (PVY)\} e vírus do enrolamento \{Potato leafroll virus (PLRV)\}. De acordo com experimentos conduzidos na Embrapa Clima Temperado para avaliação da reação dessa cultivar ao nematoide-das-galhas, 'IPR Cris' se mostrou moderadamente resistente a Meloidogyne enterolobii ( $\sin$. M. mayaguensis), resistente à $M$. graminicola, e suscetível à $M$. javanica (ensaio repetido), $M$. incognita, $M$. arenaria e $M$. ethiopica.

Como a cv. IPR Cris tem sido usada por produtores da agricultura familiar há alguns anos (Figura 1F), o nível de resistência de campo a doenças foliares

Tabela 1. Médias de rendimento de tubérculos totais e comerciais da cultivar de batata IPR Cris e cultivares testemunhas (Ágata e Cupido) (t/ha) e coeficientes de variação (CV), por local e ano \{mean yield of total and marketable tubers of potato cultivars IPR Cris and control cultivars (Ágata and Cupido), and coefficient of variation, per locality, and year\}. Curitiba, IAPAR, 2014.

\begin{tabular}{|c|c|c|c|c|c|c|c|c|c|}
\hline \multirow{2}{*}{ Local } & \multirow{2}{*}{ Safra/ano } & \multicolumn{2}{|c|}{ IPR Cris } & \multicolumn{2}{|c|}{ Ágata } & \multicolumn{2}{|c|}{ Cupido } & \multicolumn{2}{|c|}{ CV (\%) } \\
\hline & & Total & Comercial & Total & Comercial & Total & Comercial & Total & Comercial \\
\hline Pelotas & Out/09 & $13,92 \mathrm{~A}^{2}$ & $10,74 \mathrm{a}$ & $8,32 \mathrm{~B}$ & $5,29 b$ & $14,89 \mathrm{~A}$ & $12,91 \mathrm{a}$ & 13,2 & 16,8 \\
\hline Canoinhas & Out/09 & $5,07 \mathrm{~B}$ & $2,27 b$ & $3,69 \mathrm{~B}$ & $1,52 b$ & $7,94 \mathrm{~A}$ & $5,25 \mathrm{a}$ & 17,6 & 21,1 \\
\hline Lapa & Out/09 & $10,99 \mathrm{~A}$ & $3,04 \mathrm{a}$ & $3,53 \mathrm{~B}$ & $0,72 b$ & $8,86 \mathrm{~A}$ & $4,05 \mathrm{a}$ & 22,9 & 25,5 \\
\hline Pelotas & Prim/09 & $12,04 \mathrm{~A}$ & $8,11 \mathrm{a}$ & $14,40 \mathrm{~A}$ & $8,99 a$ & $10,79 \mathrm{~A}$ & $4,86 \mathrm{a}$ & 37,1 & 37,8 \\
\hline Canoinhas & Prim/09 & $19,10 \mathrm{~A}$ & $10,69 \mathrm{a}$ & $14,62 \mathrm{~A}$ & $6,77 \mathrm{a}$ & $15,88 \mathrm{~A}$ & $9,77 \mathrm{a}$ & 47,2 & 65,0 \\
\hline Lapa & Prim/09 & $15,06 \mathrm{~A}$ & $4,52 \mathrm{a}$ & $3,28 \mathrm{~B}$ & $0,22 b$ & $7,43 \mathrm{AB}$ & $1,53 \mathrm{ab}$ & 50,2 & 85,0 \\
\hline Pelotas & Out/10 & $10,05 \mathrm{~A}$ & $5,12 \mathrm{~b}$ & $10,02 \mathrm{~B}$ & $5,10 \mathrm{~b}$ & $16,19 \mathrm{~A}$ & $13,00 \mathrm{a}$ & 5,5 & 7,7 \\
\hline Canoinhas & Out/10 & $14,07 \mathrm{~A}$ & $3,21 \mathrm{a}$ & $5,67 \mathrm{~B}$ & $0,41 b$ & $7,93 \mathrm{~B}$ & $2,10 \mathrm{a}$ & 15,5 & 39,7 \\
\hline Canoinhas & Prim/11 & $26,02 \mathrm{~A}$ & $6,74 a$ & $14,77 \mathrm{~B}$ & $3,17 b$ & $17,25 \mathrm{~B}$ & $5,90 \mathrm{ab}$ & 73,3 & 21,1 \\
\hline T. Soares & Out/12 & $19,77 \mathrm{~B}$ & $15,14 b$ & $20,16 \mathrm{~B}$ & $15,26 b$ & $32,76 \mathrm{~A}$ & $28,94 \mathrm{a}$ & 20,2 & 23,4 \\
\hline \multicolumn{2}{|c|}{ Média de outono } & 12,30 & 6,59 & 8,57 & 4,72 & 14,13 & 9,59 & 24,9 & 26,6 \\
\hline Média de pr & imavera & 18,05 & 7,51 & 11,77 & 4,79 & 12,84 & 7,12 & 23,7 & 45,7 \\
\hline \multicolumn{10}{|c|}{$\mathrm{F}_{\text {(entre safras) }}:$ Produção total $=0,92 \mathrm{~ns}^{3} ;$ Produção comercial: $0,45 \mathrm{~ns}$} \\
\hline \multicolumn{2}{|l|}{ Média geral } & 14,61 & 6,96 & 9,85 & 4,75 & 13,99 & 9,47 & 29,7 & 44,0 \\
\hline
\end{tabular}

Rendimento comercial: tubérculos com diâmetro transversal $>45 \mathrm{~mm}$ (marketable yield: tubers with cross section diameter $>45 \mathrm{~mm}) ;{ }^{2}$ Médias seguidas da mesma letra (maiúsculas: rendimento total; minúsculas: rendimento comercial) nas colunas não diferem significativamente entre si, pelo teste de Fischer modificado $(p=0,05)$ \{means followed by the same letter (capital letter: total yield; small letter: commercial yield) in columns do not differ significantly from each other by the modified Fischer test $(\mathrm{p}=0,05)\}$; $\mathrm{ns}^{3}$ : Teste F da ANOVA não significativo para a comparação entre safras $\{\mathrm{F}$ ratio for growing season comparison not significant in ANOVA test $(\mathrm{p}=0,05)\}$. 
Tabela 2. Massa média de tubérculos comerciais ${ }^{1}$, em gramas, da cultivar IPR Cris e das cultivares testemunhas (Ágata e Cupido), e coeficiente de variação $(\mathrm{CV})$, por local e ano \{marketable tuber average yield, in grams, of cultivar IPR Cris and control cultivars (Ágata and Cupido), and coefficient of variation (CV), per locality, and year\}. Curitiba, IAPAR, 2014.

\begin{tabular}{lccccc}
\hline Local & Safra/ano & IPR Cris & Ágata & Cupido & CV (\%) \\
\hline Pelotas & Out/09 & $104,46 \mathrm{~b}^{2}$ & $87,85 \mathrm{bc}$ & $140,96 \mathrm{a}$ & 2,53 \\
Canoinhas & Out/09 & $105,43 \mathrm{~b}$ & $107,25 \mathrm{~b}$ & $157,94 \mathrm{a}$ & 8,69 \\
Lapa & Out/09 & $111,11 \mathrm{~ns}^{3}$ & $105,95 \mathrm{~ns}$ & $145,44 \mathrm{~ns}$ & 22,19 \\
Pelotas & Prim/09 & $85,71 \mathrm{~ns}$ & $91,11 \mathrm{~ns}$ & $77,23 \mathrm{~ns}$ & 11,10 \\
Canoinhas & Prim/09 & $150,59 \mathrm{~ns}$ & $153,19 \mathrm{~ns}$ & $132,14 \mathrm{~ns}$ & 29,43 \\
Lapa & Prim/09 & $125,39 \mathrm{~ns}$ & $66,67 \mathrm{~ns}$ & $101,90 \mathrm{~ns}$ & 38,25 \\
Pelotas & Out/10 & $76,13 \mathrm{c}$ & $84,74 \mathrm{~b}$ & $105,32 \mathrm{a}$ & 4,62 \\
Canoinhas & Out/10 & $98,52 \mathrm{~ns}$ & $101,60 \mathrm{~ns}$ & $122,76 \mathrm{~ns}$ & 12,16 \\
Canoinhas & Prim/11 & $423,03 \mathrm{~ns}$ & $174,54 \mathrm{~ns}$ & $205,13 \mathrm{~ns}$ & 71,37 \\
T. Soares & Out/12 & $135,66 \mathrm{~ns}$ & $133,81 \mathrm{~ns}$ & $185,26 \mathrm{~ns}$ & 25,48 \\
\hline Média de outono & & 105,22 & 103,53 & 142,89 & 12,61 \\
Média de primavera & & 196,18 & 121,38 & 129,10 & 28,80 \\
F $_{\text {(entre safras }}: 0,92 \mathrm{~ns}^{4}$ & & & & 19,58 \\
Média geral & & 117,60 & 102,67 & 117,41 & \\
\hline
\end{tabular}

${ }^{1}$ Tubérculo comercial: diâmetro transversal $>45 \mathrm{~mm}$ (marketable tuber: cross section diameter $>45 \mathrm{~mm}$ ); ${ }^{2}$ Médias seguidas da mesma letra nas colunas não diferem significativamente entre si, pelo teste de Fischer modificado $(p=0,05)$ \{means followed by the same letter in columns do not differ significantly from each other by the modified Fischer test $(\mathrm{p}=0,05)\}$; ns $\mathrm{s}^{3}$ : Teste F da ANOVA não significativo para a média de tratamentos $\{\mathrm{F}$ ratio for treatment means not significant in ANOVA test $(\mathrm{p}=0,05)\} ; \mathrm{ns}^{4}$ : Teste $\mathrm{F}$ da ANOVA não significativo para a comparação entre safras $\{\mathrm{F}$ ratio for growing season comparison not significant in ANOVA test $(\mathrm{p}=0,05)\}$.

Tabela 3. Massa específica ${ }^{1}$ de tubérculos da cultivar IPR Cris e das testemunhas (Ágata e Cupido), e coeficiente de variação (CV), por local e ano \{specific gravity ${ }^{1}$ of cultivar IPR Cris and control cultivars (Ágata and Cupido), and coefficient of variation (CV), per locality, and year\}. Curitiba, IAPAR, 2014.

\begin{tabular}{llllll}
\hline Local & Safra/ano & IPR Cris & Ágata & Cupido & CV (\%) \\
\hline Pelotas & Out/09 & $1,0647 \mathrm{~ns}^{2}$ & $1,0680 \mathrm{~ns}$ & $1,0680 \mathrm{~ns}$ & 0,39 \\
Canoinhas & Out/09 & 1,0810 & 1,0690 & 1,0770 & $-_{--^{3}}$ \\
Lapa & Out/09 & $1,0622 \mathrm{~ns}$ & $1,0876 \mathrm{~ns}$ & $1,0703 \mathrm{~ns}$ & 3,12 \\
Pelotas & Prim/09 & 1,0890 & 1,0750 & 1,0600 & --- \\
Canoinhas & Prim/09 & $1,0830 \mathrm{a}^{4}$ & $1,0625 \mathrm{c}$ & $1,0723 \mathrm{~b}$ & 0,30 \\
Lapa & Prim/09 & $1,0799 \mathrm{a}$ & $1,0647 \mathrm{~b}$ & $1,0631 \mathrm{~b}$ & 0,54 \\
Pelotas & Out/10 & $1,0713 \mathrm{~ns}$ & $1,0553 \mathrm{~ns}$ & $1,0660 \mathrm{~ns}$ & 0,72 \\
Canoinhas & Out/10 & $1,0840 \mathrm{~ns}$ & $1,0633 \mathrm{~ns}$ & 1,0703 & 0,31 \\
Canoinhas & Prim/11 & $1,0890 \mathrm{~ns}$ & $1,0733 \mathrm{~ns}$ & $1,0793 \mathrm{~ns}$ & 0,05 \\
T. Soares & Out/12 & $1,0767 \mathrm{a}$ & $1,0548 \mathrm{~b}$ & $1,0667 \mathrm{ab}$ & 12,20 \\
\hline Média de outono & & 1,0733 & 1,0663 & 1,0697 & 3,35 \\
Média de primavera & & 1,0852 & 1,0689 & 1,0687 & 0,30 \\
$\mathrm{~F}_{\text {(entre safras) }}: 2,06 \mathrm{~ns}^{5}$ & & & & \\
Média geral & & 1,0781 & 1,0674 & 1,0693 & 2,20 \\
\hline
\end{tabular}

${ }^{1}$ Massa específica $=$ Peso ao ar/(peso ao ar - peso em água) $\{$ specific gravity $=$ weight in air/(weight in air - weight immersed in water) $\}$; ${ }^{2}$ ns: Teste F da ANOVA não significativo para a média de tratamentos $\{\mathrm{F}$ ratio for treatment means not significant in $\mathrm{ANOVA}$ test $(\mathrm{p}=0,05)\}$; ${ }^{3}$ Dado de uma amostragem somente \{data of only one sample $\} ;{ }^{4}$ Médias seguidas da mesma letra nas colunas não diferem significativamente entre si, pelo teste de Fischer modificado $(\mathrm{p}=0,05)$ \{means followed by the same letter in columns do not differ significantly from each other by the modified Fischer test $(\mathrm{p}=0,05)\} ;{ }^{5} \mathrm{~ns}$ : Teste $\mathrm{F}$ da ANOVA não significativo para a comparação entre safras $\{\mathrm{F}$ ratio for growing season comparison not significant in ANOVA test $(\mathrm{p}=0,05)\}$. 


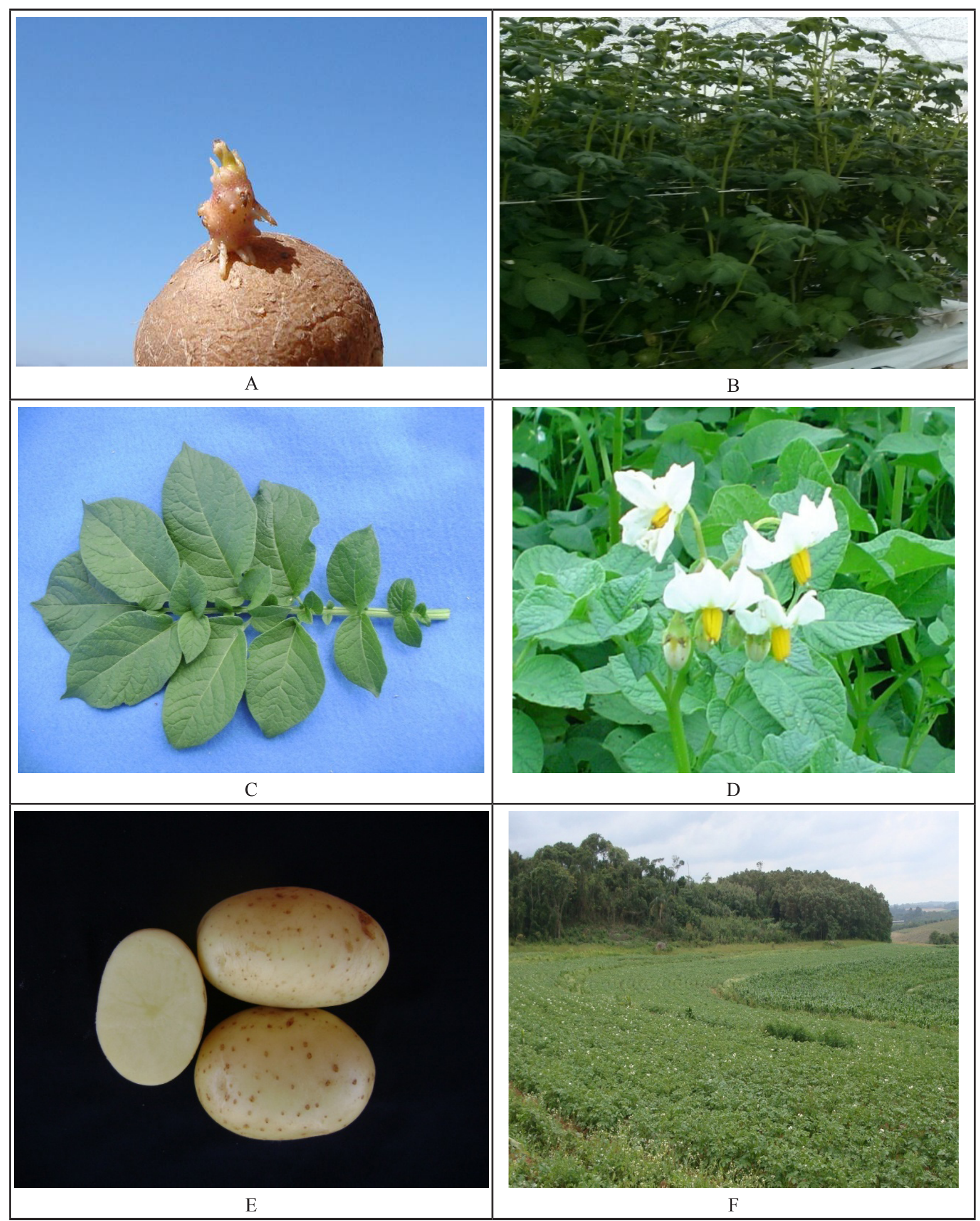

Figura 1. Cultivar IPR Cris: (A) Broto cilíndrico, vermelho púrpura na base (cylindrical sprout, reddish purple at the base), (B) Planta de porte ereto (plant of stout growth), (C) Folhas abertas, nervura não pigmentada, folíolos médios, não coalescentes (open leaves, non pigmented midrib, non coalescent leaflets), (D) Flores de corolas brancas, sem pigmentação interna (flowers with white corola, without internal pigmentation), (E) Tubérculos ovalados, polpa amarela clara, gemas rasas (oval shaped tubers, yellowish pulp, shallow eyes), (F) Campo de produção no sistema orgânico (potato crop under organic production system). Curitiba, IAPAR, 2014. 
tem sido comprovado, com algum relato informando ser desnecessário o controle com caldas fungicidas em épocas de produção mais secas (Nazareno \& Pereira, 2009).

\section{DESEMPENHO AGRONÔMICO}

Tanto na produção total como na comercial 'IPR Cris' foi superior à testemunha 'Ágata' em sete dos dez experimentos (Tabela 1), superior somente na produção total em Pelotas, outono/2010, e igual em Teixeira Soares. Essa cultivar foi também igual à 'Cupido' em seis experimentos, mas foi superior em produção total em dois e inferior em outros dois, tanto em produção total como comercial. Esse comportamento corrobora o potencial de 'IPR Cris' como cultivar produtiva, principalmente porque o foco de produção é para sistemas orgânicos principalmente, onde 'Ágata' e 'Cupido' são mais suscetíveis à requeima em comparação à 'IPR Cris'. Não houve diferença significativa entre safras, nem para produção total $(\mathrm{F}=0,92 \mathrm{~ns})$ como para produção comercial ( $\mathrm{F}=0,45 \mathrm{~ns})$.

Como o potencial de 'IPR Cris' é para produção em sistema de subsistência, a quantidade de insumos nos experimentos foi reduzida ( $2 \mathrm{t} /$ ha do formulado 4-14-8 de adubação de base e $60 \mathrm{~kg} / \mathrm{ha}$ de sulfato de amônio em cobertura e pulverizações semanais com fungicidas de contato). Por isso, acredita-se que a tendência a menores produtividades da testemunha 'Ágata' foi devido à pressão da requeima, doença à qual ela é muito suscetível. Em experimento conduzido no norte do Paraná, em Londrina, na safra de inverno, as produções total e comercial de 'IPR Cris' foram de 46,83 e $31,99 \mathrm{t} / \mathrm{ha}, 42,1$ e $25,1 \%$ a mais que 'Ágata' e 7,5 e 19,0\% a menos que 'Cupido', respectivamente (dados não publicados).

$\mathrm{Na}$ Tabela 2 registra-se a massa média de tubérculos comerciais, variável importante a considerar na indicação de cultivares. Observou-se que 'IPR
Cris' foi em grande parte equivalente às testemunhas, mas em alguns locais foi inferior à 'Cupido', cultivar que tem potencial genético para produção de tubérculos grandes. Porém, na média geral, 'IPR Cris' foi equivalente à cv. Cupido. A ANOVA global entre todos os experimentos não detectou diferenças significativas entre safras $(\mathrm{F}=0,92 \mathrm{~ns})$.

A Tabela 3 contempla os valores estimados da massa específica. Em grande parte dos experimentos 'IPR Cris' foi igual às cultivares testemunhas. Todavia, nos casos onde houve diferença significativa entre elas, 'IPR Cris' foi sempre melhor que 'Ágata' e 'Cupido'. Na comparação entre safras, não houve diferença estatística para massa específica $(\mathrm{F}=2,06 \mathrm{~ns})$.

Os dados observados em todos os experimentos e a experiência de produtores familiares que vêm testando 'IPR Cris' há algum tempo em suas propriedades, indicam o grande potencial dessa cultivar para o sistema orgânico de produção dada a sua rusticidade a doenças foliares, à sarna comum, a boa aparência de tubérculo e sua resistência ao armazenamento prolongado. A característica de longo período de dormência facilita a comercialização escalonada no nicho de mercado que disponibilizam (Nazareno \& Pereira, 2009), à medida que a colheita pode ser parcelada em pequenos lotes por períodos de até 60 dias após a maturação fisiológica, sem perder a qualidade comercial dos tubérculos (Nazareno, 2009).

\section{MANEJO}

'IPR Cris' não apresenta característica diferencial em relação a cultivares convencionais, exceto pela sua longa dormência. Para o cultivo em sistema orgânico, a quebra de dormência tem sido feita deixando os tubérculos em estaleiros em ambiente bem ventilado e pouca luz por períodos que ultrapassam seis meses. Alguns produtores estufam os tubérculos sob lonas plásticas com alguma forma de aquecimento na pilha enlonada, como carvão em brasa, cobertura dos tubérculos com camadas de capim e/ou fazem o abafamento em lugar onde haja incidência solar direta (Nazareno, 2009). Não existem dados de indução de brotação com métodos químicos para o caso de uso dessa cultivar em sistema convencional de produção (Hirano et al., 1996).

\section{SEMENTE}

A preservação de tubérculos-semente G0, devidamente indexados, é feita em estufa específica para batata, no sistema de hidroponia na estação experimental do Iapar na Lapa, PR.

\section{REFERÊNCIAS}

HIRANO E; BERTONCINI O; PEREIRA VL. 1996. Brotação: armazenamento e quebra de dormência em batata-semente. Canoinhas: Embrapa SNT/EN.

IAPAR. 2014. IPR CRIS - Cultivar de batata para produção orgânica. Londrina: IAPAR (Folder).

MAPA. 2007. Registro Nacional de Cultivares RNC. Brasília, DF. Orientações e Informações Técnicas. p. 18. Anexo III - Batata (http:// www.agricultura.gov.br/arq_editor/file/ vegetal/Sementes_e_mudas/Registro_ Nacional_de_Cultivares.pdf). Acessado em 31 de janeiro de 2009.

MEDEIROS CAB. 2002. Produção de sementes pré-básicas de batata em sistema hidropônico de telhas de fibrocimento: Densidade de plantas para multiplicação a partir de minitubérculos. Pelotas: Embrapa Clima Temperado (http:// www.infoteca.cnptia.embrapa.br/bitstream/ doc/744350/1/comunicado69.pdf. Acessado em 31 de janeiro 2014.

NAZARENO NRX. 2009. Contribuição dos produtores: Levantamento sobre suas experiências. In: Produção Orgânica de Batata - Potencialidades e desafios (N.R.X Nazareno, Ed). Iapar, Londrina. p. 235-249.

NAZARENO NRX; PEREIRA AS. 2009. Cultivares de batata adaptadas ao sistema orgânico de produção. In: NAZARENO NRX (ed). Produção orgânica de batata Potencialidades e desafios. Iapar: Londrina. p. 109-120.

PEREIRA AS; SILVA ACF; CASTRO CM; MEDEIROS CAB; HIRANO E; NAZARENO NRX; BERTONCINI O; MELO PE; SOUZA ZS. 2008. Catálogo de cultivares de batata. Pelotas: Embrapa Clima Temperado. (Documentos 247, p.40) (http://www.infoteca. cnptia.embrapa.br/bitstream/doc/746700/1/ documento247.pdf). Acessado em 31 de maio de 2014 